\title{
Step by step
}

\author{
Fred Bosman
}

Received: 8 December 2013 / Accepted: 13 December 2013 / Published online: 3 January 2014

(C) Springer-Verlag Berlin Heidelberg 2014

Another year has passed by in the life of your respectable journal, during which its 463rd volume was published, and in the life of its latest Editor in Chief, for whom this Editor position has become a very essential part of his daily activities. Few things happen spontaneously and to make the journal sail, a defined course requires an effort. Authors write and submit what they want to communicate, which might not always be what the Editor is looking for. To fine-tune papers, interacting with authors to improve their paper to get it closer to the standards we are dreaming of is a time-consuming activity. But it is also immensely rewarding. The feedback from readers on the direction the journal has taken has been very positive.

So what have we achieved this year? To begin with, the impact factor went up again. The annual increments over the last 5 years were small, but the trend is unmistakable. The journal is gradually more and more appreciated. The impact factor, however, is by no means the only parameter of importance in terms of the standing of the journal. As a vehicle of scientific communication between members of the European Society of Pathology, what the journal publishes should be appreciated by its readers. We will therefore continue to publish papers that might not be cited very much. History of Pathology is an example. Position papers on issues of more general (e.g. ethical, legal, societal) importance are another example. What this implies is that we are gradually translating the very generically phrased aims and scope of the journal into a tangible publication strategy.

How does the Editorial Committee (Editor in Chief and Associate Editors) go about this? Well, we had a second strategy meeting just before the European Congress in Lisbon.

F. Bosman $(\bowtie)$

Institut Universitaire de Pathologie, Centre Hospitalier Universitaire

Vaudois, Lausanne, Switzerland

e-mail: fred.bosmanx@chuv.ch
Main issues during that meeting were what we perceive to be the journal now and what we would like it to become. What clearly emerged from the reader survey that we conducted a couple of years ago is the importance of reviews. For many of our readers, the journal is one of the key elements in keeping informed as to the developments in our discipline and that is exactly what reviews should offer. We therefore defined a more detailed review policy. First of all, each year a review issue will be published. The 2014 review issue will see the light of day early on in the New Year, if all goes well not later than February. The theme chosen is Prognostic (and to a lesser extent Predictive) Biomarkers. Timely topics have been identified for the following years. A second action has been expanding the number of invited reviews. The result of this should be at least one review in each monthly issue. The choice of review topics is quite important. Reviews with updates on advances in diagnostic pathology emerged from the survey as being highly appreciated, so that has been the main focus in inviting experts to write reviews. We will continue, however, to publish reviews also on mechanisms of disease. No one will contest the notion that diagnosing a disease through examination of cells and tissues should be based upon understanding the disease. A third element in preparation is the teaching case of the month. The format is still under development, but the idea is to do this in the form of a quiz: case history and diagnostic material in one issue (along with virtual slides that can be consulted on the e-learning portal of the ESP) and the final diagnosis with expert comments in the next issue.

Among the comments I have received on Virchows Archiv, an issue that continues to emerge, is what it looks like. What emerges is that many of you do not appreciate the actual cover, not for its colour, not for the make-up, perceived as somewhat outdated, and not for the content list on the back cover. We are therefore in a process of redesigning the cover. The colour will change, Euro blue to reinforce the notion of 'European 
Journal of Pathology'. European Journal of Pathology will be more prominent, although Virchows Archiv will remain as the title. There will be more information on the front cover, and the complete content on the back cover will be more legible. We need to maintain the ties with history but also anticipate the future. We cater to a generation of pathologists that will see pathology change even more than my generation has seen. Open orientation towards dynamic evolution of our discipline should be part of the journal's identity.

The Editorial Committee will also see some modifications. Some Associate Editors are leaving us. Pierre Bedossa has been a member of the crew for a very long time. Virchows Archiv is deeply grateful for all the time and energy he has dedicated over the years to maintain quality and further develop our journal. During the Lisbon congress, he has been elected President-elect of the European Society of Pathology. We wish him the best of luck and much satisfaction in serving the society. Sunil Lakhani has decided to leave the Editorial Committee before the end of his term. He felt that the level of overcommitment he had gradually diffused into had become incompatible with the amount of time the journal effectively requires, not only in terms of 'pushing' manuscripts through the editorial system but also and maybe even, more so, in terms of active participation in shaping the future of the journal. We thank Sunil for the time and energy he has dedicated to the journal and wish him well in his professional endeavours. Others have come in and more will be coming in over the next few months. Ales Ryska has gone through a trial period (to see if the workload would not get him into the proverbial state of overcommitment) and the experience made him decide to join the team. Welcome Ales! He will be responsible for the teaching case series. We will recruit a Reviews Editor, recognizing that delivering the annual review issue and monthly reviews on timely topics requires a considerable effort.

For the journal, 2014 is going to be an exciting year. We wish that for all of you this New Year will be full of pleasant surprises. Make it a happy one! 